\title{
Immortal time bias: a possible explanation for "Impact of acyclovir use on survival of patients with ventilator-associated pneumonia and high load herpes simplex virus replication"
}

\author{
Magnus Glindvad Ahlström ${ }^{1 *}$, Lars Haukali Omland ${ }^{2}$, Andreas Ronit ${ }^{3}$ and Niels Obel ${ }^{2}$
}

Dear editor,

We have with great interest read the paper "Impact of acyclovir use on survival of patients with ventilatorassociated pneumonia and high load herpes simplex virus replication" published recently in Critical Care [1]. The study describes impact of acyclovir treatment on mortality in patients with ventilator-associated pneumonia who tested positive for herpes simplex virus in respiratory secretions. The authors conclude that treatment with acyclovir in patients with high HSV viral load decreases mortality in this population dramatically.

The authors address an important scientific question. However, we have concerns regarding the statistical analyses of survival. The authors seem to separate patients in acyclovir treated and not treated patients. This statistical strategy may lead to immortal time bias, which is a bias that results in substantial overestimation of the effect of medical treatment [2, 3]. Even for medical treatment without effect, that bias may lead to large estimates that are "statistically significant". We identified potential scenarios in the current study in which immortal time bias could occur: (1) acyclovir treatment precedes HSV-positive test leading to immortal time included in the acyclovir treated group (Fig. 1a) and (2) HSV-positive test precedes acyclovir treatment leading to immortal time excluded from the untreated group (Fig. 1b), both of which would lead to an "artificial" survival advantage for the treated group.

We therefore suggest that the authors reanalyze their data, in which they start observation at the date of test for herpes simplex virus and include acyclovir treatment as a time updated exposure.

* Correspondence: magnus.rasch@gmail.com

'Department of Clinical Microbiology, Copenhagen University Hospital, Rigshospitalet, Copenhagen, Denmark

Full list of author information is available at the end of the article 
A

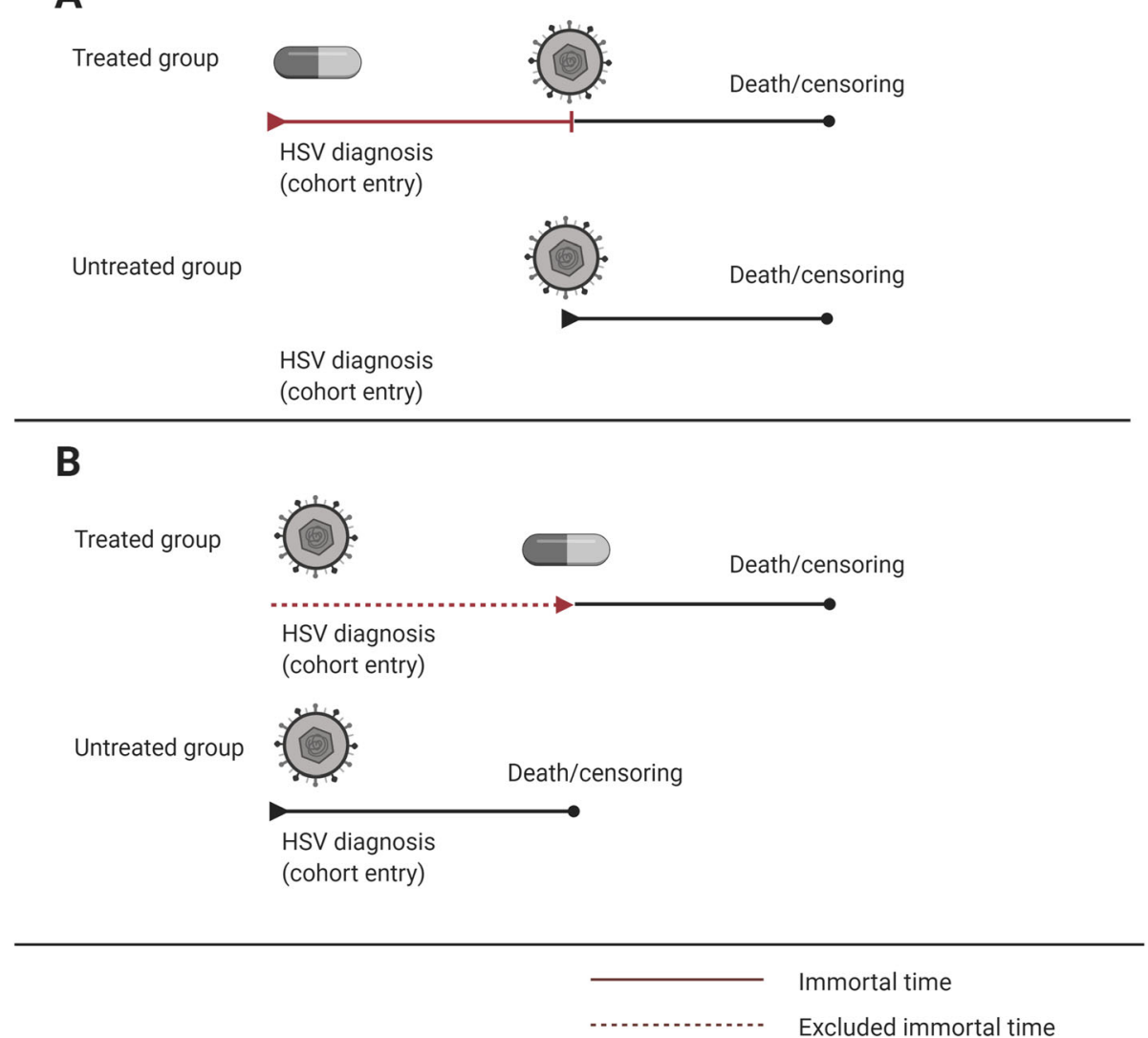

Fig. 1 Potential immortal time bias in the current study. a Acyclovir treatment preceding HSV test, time is started at acyclovir treatment leading to an immortal time from start of treatment to HSV test. $\mathbf{b}$ HSV test preceding acyclovir treatment leading to excluded immortal time from the untreated group

\section{Acknowledgements}

None.

\section{Authors' contributions}

MGA identified the potential problem. All authors contributed to the discussion of the problem, wrote initial drafts, and approved the final manuscript.

\section{Funding}

None.

\section{Availability of data and materials}

Not applicable.

\section{Ethics approval and consent to participate}

Not applicable.

\section{Consent for publication}

Not applicable.

\section{Competing interests}

All authors report no competing interests.

\section{Author details}

${ }^{1}$ Department of Clinical Microbiology, Copenhagen University Hospital, Rigshospitalet, Copenhagen, Denmark. '2Department of Infectious Diseases, Copenhagen University Hospital, Rigshospitalet, Copenhagen, Denmark ${ }^{3}$ Department of Infectious Diseases, Copenhagen University Hospital, Hvidovre Hospital, Hvidovre, Denmark.
Received: 24 May 2020 Accepted: 8 June 2020

Published online: 17 June 2020

\section{References}

1. Schuierer $L$, et al. Impact of acyclovir use on survival of patients with ventilator-associated pneumonia and high load herpes simplex virus replication. Crit Care Lond Engl. 2020;24:12.

2. Suissa S. Immortal time bias in pharmaco-epidemiology. Am J Epidemiol. 2008;167:492-9.

3. Rothman KJ, Greenland S, Lash TL. Modern epidemiology - 3rd Ed. Wolters Kluwer Health, Lippincott Williams \& Wilkins;2008.

\section{Publisher's Note}

Springer Nature remains neutral with regard to jurisdictional claims in published maps and institutional affiliations. 